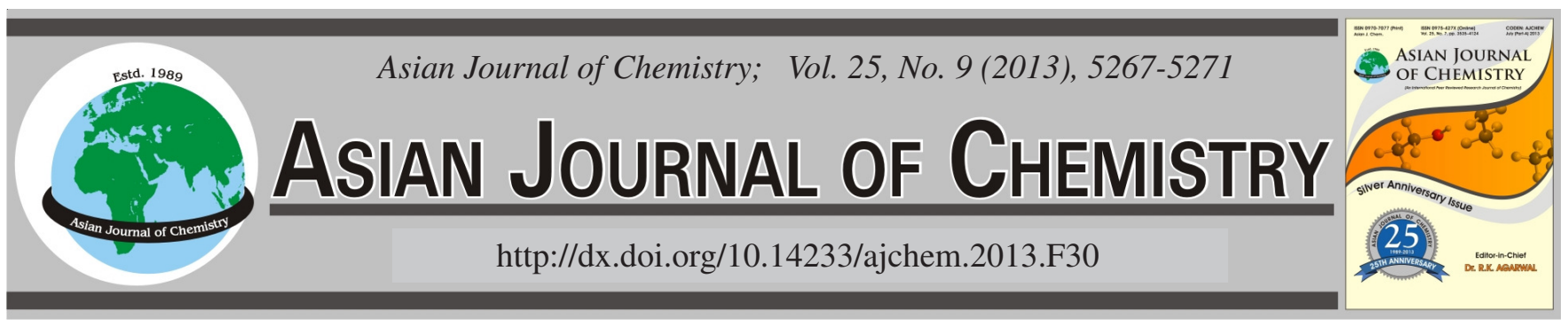

\title{
Comonomer Effects of High $\alpha$-Olefins in Metallocene Catalyzed Terpolymerization: Thermal Properties $\dagger$
}

\begin{abstract}
D.H. KIM
Convergent Technology R \& D Division, Korea Institute of Industrial Technology, Ansan-si, Republic of Korea

Corresponding author: Fax: +82 31 80406239; Tel: +82 31 80406226; E-mail: dhkim@kitech.re.kr

A range of polymers were synthesized using a rac-Et(Ind) $\mathrm{ZrCl}_{2}$ catalyst and methylaluminoxane co-catalyst system. The polymers, homo-, co- and terpolymers were comprised of ethylene, 1-decene and $p$-methyl styrene. The structures and compositions of the polymers were examined by ${ }^{13} \mathrm{C}$ nuclear magnetic spectroscopy and ${ }^{1} \mathrm{H}$ nuclear magnetic spectroscopy. The catalytic activity, weight-averaged molecular weight, number-averaged molecular weight and molecular weight distribution of the polymers were characterized. The glass transition temperature, melting temperature, crystallization temperature, crystallinity, storage modulus, loss modulus and tan $\delta$ of the terpolymers according to the 1-decene feed molar concentration were also examined.
\end{abstract}

Key Words: Polyolefins, Elastomers, Catalyst, Comonomer, Metallocene.

ᄂ - - - - - - - - - - - - - - - - - - - - - - - - - - - -

\section{INTRODUCTION}

Research on polymerization using a metallocene catalysts began with the identification of the structure of ferrocene by Wilkins and Fischer in 1952 and was developed further by Kaminsky in the $1980 \mathrm{~s}^{1,2}$. In the case of copolymerization using a metallocene catalyst, preparing polymers with a narrow molecular weight distribution, high stereo-regularity and uniform comonomer incorporation is much easier than when a conventional Ziegler-Natta catalyst is used. This can explain why many studies have examined coordination polymerization using metallocene catalysts.

On the other hand, these studies focused mainly on the copolymerization of ethylene with high- $\alpha$-olefin, diene monomer, cyclo-olefin and styrene. In addition, other studies have examined the copolymerization of propylene with ethylene and high- $\alpha$-olefin. The main research on the terpolymer was the effect of termonomers on the properties of EPDM-rubber or block-terpolymers. In particular, a study on the terpolymer with reactive groups is limited, even though the terpolymer can be use to develop new high-functional polyolefinic elastomers $^{3-12}$.

In this study, homo-, co- and terpolymers were prepared using a bridged metallocene catalyst and cocatalyst system according to the changes in the feed molar concentration of ethylene, 1 -decene and $p$-methyl styrene. These results were compared with the thermal properties of the terpolymers, focusing on the comonomer effects of 1-decene.

EXPERIMENTAL

All manipulations were carried out in an inert nitrogen atmosphere. High-purity grade ethylene gas (Dae-myung Gas Co.) was used after passing it through an alumina/zeolite column. 1-Decene (Aldrich, $94 \%$ ), $n$-hexane (SAMCHUN, $99.5 \%$ ) and toluene (SAMCHUN, $99.5 \%$ ) were purified by heating them over sodium under reflux, using benzophenone as an indicator and stored in a dry box. A solution of rac$\mathrm{Et}(\mathrm{Ind})_{2} \mathrm{ZrCl}_{2}$ (Sigma Aldrich) in toluene was also prepared. $p$-methyl styrene ( $p$-MS) was distilled under reduced pressure in the presence of $\mathrm{CaH}_{2}$ after performing the standard purification procedure. The specimens for thermal and wide-angle $\mathrm{X}$-ray scattering analyses were prepared by compression molding in a hot press.

Typically, all the polymerization reactions were carried out in a $300 \mathrm{~mL}$ stainless steel autoclave with a mechanical stirrer.

After saturating the autoclave with ethylene gas, polymerization was initiated by injecting the required amount of the monomers, catalyst solution and methylaluminoxane (MAO). After several minutes, the polymer solution was poured into a diluted $\mathrm{HCl} / \mathrm{EtOH}$ solution. The resulting polymer was washed with $\mathrm{EtOH}(600 \mathrm{~mL})$ and dried in vacuo. 
TABLE-1

SUMMARY OF POLYMERIZATION USING a $r a c$-Et(Ind) ${ }_{2} \mathrm{ZrCl}_{2} / \mathrm{MAO}$ SYSTEM

\begin{tabular}{|c|c|c|c|c|c|c|c|c|c|c|c|}
\hline \multirow{2}{*}{ Run No. ${ }^{\mathrm{a}}$} & \multicolumn{3}{|c|}{ Monomer (mol/L) } & \multirow{2}{*}[\mathrm{D}^{\mathrm{c}}]{$/\left[\mathrm{M}^{\mathrm{d}}\right]$} & \multirow{2}{*}{$\begin{array}{l}\text { Catalytic } \\
\text { activity }^{\mathrm{e}}\end{array}$} & \multirow{2}{*}{$\begin{array}{c}\mathrm{Mw}^{\mathrm{f}} \\
(\mathrm{kg} / \mathrm{mol})\end{array}$} & \multirow{2}{*}{$\begin{array}{c}\mathrm{Mn}^{\mathrm{f}} \\
(\mathrm{kg} / \mathrm{mol})\end{array}$} & \multirow{2}{*}{$\mathrm{MWD}^{\mathrm{f}}$} & \multicolumn{3}{|c|}{ Compositions of the polymers ${ }^{\mathrm{h}}(\%)$} \\
\hline & $E^{b}$ & $\mathrm{D}^{\mathrm{c}}$ & $\mathrm{M}^{\mathrm{d}}$ & & & & & & $E^{b}$ & $\mathrm{D}^{\mathrm{c}}$ & $\mathrm{M}^{\mathrm{d}}$ \\
\hline 1 & 0.4 & 0 & 0 & 0.00 & 1420 & - & - & - & 100 & 0.00 & 0.00 \\
\hline 2 & 0.1 & 0.4 & 0.4 & 1.00 & 1120 & 74093 & 33832 & 2.19 & 76.9 & 20.1 & 3.0 \\
\hline 3 & 0.2 & 0.4 & 0.4 & 1.00 & 1736 & 91974 & 41360 & 2.22 & 80.9 & 15.8 & 3.3 \\
\hline 4 & 0.3 & 0.4 & 0.4 & 1.00 & 2464 & 96650 & 42709 & 2.26 & 82.1 & 14.7 & 3.2 \\
\hline 5 & 0.4 & 0.4 & 0.4 & 1.00 & 2648 & 100871 & 37529 & 2.68 & 84.2 & 13.4 & 2.4 \\
\hline 6 & 0.4 & 0 & 0.4 & 0.00 & 350 & 85000 & 26000 & 3.30 & 97.6 & 0 & 2.4 \\
\hline 7 & 0.4 & 0.2 & 0.4 & 0.50 & 560 & 100256 & 36456 & 2.75 & 85.2 & 12.5 & 2.3 \\
\hline 8 & 0.4 & 0.6 & 0.4 & 1.50 & 3176 & 102943 & 31797 & 2.63 & 86.2 & 12.4 & 1.4 \\
\hline 9 & 0.4 & 0.8 & 0.4 & 2.00 & 5400 & 89995 & 28273 & 3.18 & 83.5 & 14.8 & 1.7 \\
\hline
\end{tabular}

${ }^{\mathrm{a}}$ Polymerization conditions: $\mathrm{rac}$-Et(Ind) ${ }_{2} \mathrm{ZrCl}_{2}, \mathrm{MAO}$, catalyst $=2.5 \mu \mathrm{mol},[\mathrm{Al}] /[\mathrm{Zr}]=3000,50{ }^{\circ} \mathrm{C}$ and $30 \mathrm{~min} ;{ }^{\mathrm{b}} \mathrm{Ethylene} ;{ }^{\mathrm{c}} 1-\mathrm{decene} ;{ }^{\mathrm{d}} p$ methylstyrene; ${ }^{\mathrm{c}}$ Catalytic activity $=\mathrm{kg}$ of polymer/(mol of catalyst $\left.\cdot \mathrm{h}\right) ;{ }^{\mathrm{f}}$ Determined by gel permeation chromatography

Each soluble terpolymer was separated from the insoluble polyethylene (some types of by-products) using a Soxhlet apparatus and $n$-hexane as a solvent. The pure terpolymer was obtained after drying the soluble fractions. The terpolymer was completely soluble in common organic solvents, such as hexane, toluene and tetrahydrofuran.

Fourier transformed infrared (FT-IR) spectroscopy was performed using a Thermo Scientific Co. NICOLET 6700 spectrometer. ${ }^{13} \mathrm{C}$ and ${ }^{1} \mathrm{H}$ nuclear magnetic resonance (NMR, Bruker AVANCE) spectroscopy was carried out at $60^{\circ} \mathrm{C}$ at a frequency of 400 and $500 \mathrm{MHz}$, respectively. The sample solutions of the polymer were prepared in $\mathrm{CDCl}_{3}$. The deuterated solvent was used to provide an internal lock signal. The number-averaged molecular weight, weight-averaged molecular weight and molecular weight distribution of the polymers were measured by gel permeation chromatography (Polymer Laboratories Co. PL-GPC210) fitted with Styragel (olesis guard column) HT-type columns. The analyses were performed at $140{ }^{\circ} \mathrm{C}$ and $1.0 \mathrm{~mL} / \mathrm{min}$ with 1,2,4-trichloro benzene as the solvent. Differential scanning calorimetry (DSC) of the terpolymers was performed using a DSC7 (PERKIN ELMER Co.). The samples were heated from 0 to $150{ }^{\circ} \mathrm{C}$ and then cooled to $0{ }^{\circ} \mathrm{C}$ at $10^{\circ} \mathrm{C} / \mathrm{min}$. Subsequently, they were reheated to $150{ }^{\circ} \mathrm{C}$ at $10^{\circ} \mathrm{C} / \mathrm{min}$. The crystallization temperature $\left(\mathrm{T}_{\mathrm{c}}\right)$, melting temperature $\left(\mathrm{T}_{\mathrm{m}}\right)$ and enthalpy of fusion $\left(\Delta \mathrm{H}_{\mathrm{m}}\right)$ were derived from the second and third run curves. The measured $\Delta \mathrm{H}_{\mathrm{m}}$ was converted to the degree of crystallinity $(1-\lambda)_{\Delta \mathrm{H}}$ using $290 \mathrm{~J} / \mathrm{g}$ as the enthalpy of fusion of a perfect polyethylene crystal $^{13}$.

Wide-angle X-ray scattering (WAXS, Rigaku D/MAX$2200 \mathrm{~V}$ ) patterns were recorded in reflection mode at room temperature. The instrument used a $\mathrm{Cu}$ source at $40 \mathrm{kV}$ and $40 \mathrm{~mA}$. The diffraction scans were collected over a period of $20 \mathrm{~min}$ between 3.0 and $40.0^{\circ} 2 \theta$ at a sampling rate of $2 \% \mathrm{~min}$. The dynamic mechanical spectra of the samples were obtained by dynamic mechanical analysis (DMA) (Seiko Co., Exstar $6000)$ over the temperature range, -60 to $60^{\circ} \mathrm{C}$. The specimens were analyzed in tension mode at a constant frequency of $1 \mathrm{~Hz}$ with $0.01 \%$ strain at a heating rate of $2{ }^{\circ} \mathrm{C} / \mathrm{min}$.

\section{RESULTS AND DISCUSSION}

Scheme-I shows the synthetic procedures for the synthesis of poly(ethylene-ter-1-decene-ter-p-methylstyrene) using a metallocene catalyst and cocatalyst system. A bridged-type
rac-Et(Ind) ${ }_{2} \mathrm{ZrCl}_{2}$ and methylaluminoxane (MAO) was used as the metallocene catalyst and cocatalyst, respectively.

The most interesting aspect of these zirconocene metallocene-methylaluminoxane systems is the production of random copolymers with higher catalytic activities. The $\mathrm{C} 2$ symmetric metallocene catalyst, rac-Et(Ind) ${ }_{2} \mathrm{ZrCl}_{2}$, has a relatively electron-rich indenyl ligand, which stabilizes the transition metals of the catalyst with cationic character. This increases the catalytic activity of rac-Et(Ind) ${ }_{2} \mathrm{ZrCl}_{2}$ compared to that of the other complexes.

Table-1 lists the results of polymerization using a rac$\mathrm{Et}(\mathrm{Ind})_{2} \mathrm{ZrCl}_{2}$ and methylaluminoxane system. The changes in the catalytic activity, weight-average molecular weight, number-averaged molecular weight, molecular weight distribution and compositions of the polymers were investigated as a function of the ethylene pressure and 1-decene feed molar concentration.

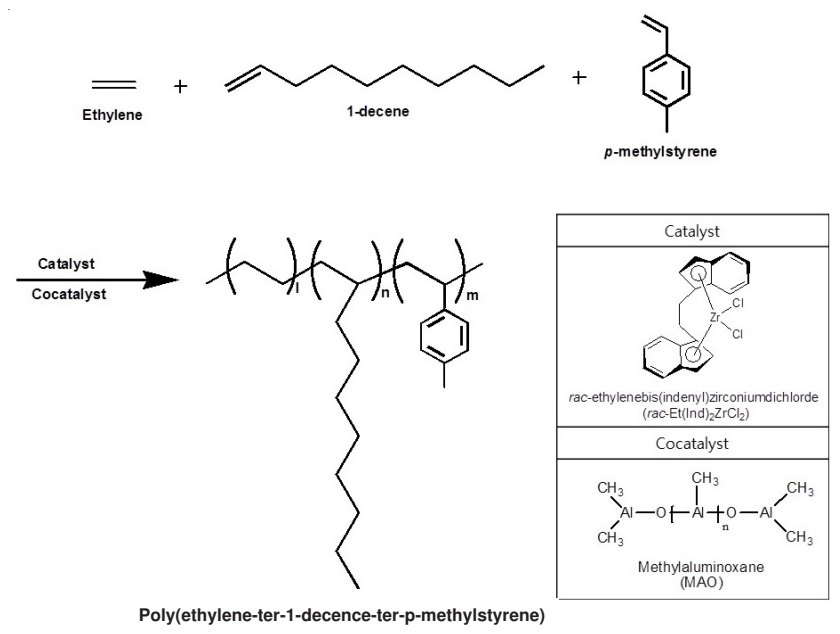

Scheme-I: Synthetic procedures for the poly(ethylene-ter-1-decene-ter- $p$ methylstyrene)

The catalytic activity, weight-average molecular weight and molecular weight distribution of the terpolymers increased with increasing ethylene pressure from 0.1 to $0.4 \mathrm{~mol} / \mathrm{L}$.

As the 1-decene molar concentration was increased from 0.2 to $0.8 \mathrm{~mol} / \mathrm{L}$, the catalytic activity increased sharply, which was attributed to the positive comonomer effect. The molecular weight, molecular weight distribution of the terpolymers, showed maximum values at a 1-decene molar concentration of $0.6 \mathrm{~mol} / \mathrm{L}$. 
Fig. 1 shows two types of FT-IR spectra: (a) the spectrum of the insoluble parts produced through the soxhlet process using $n$-hexane for the terpolymer by run 5 and (b) the spectrum of the polymer by run 1 . The spectra of (a) and (b) had similar characteristic peaks for general polyethylene. The $\mathrm{C}-\mathrm{H}$ stretching peaks were present near $2850 \mathrm{~cm}^{-1}$ and $2950 \mathrm{~cm}^{-1}$. The $\mathrm{CH}_{2}$ bending peak and out of plane $\mathrm{C}$-H bending peak were observed at $1400 \mathrm{~cm}^{-1}$ and $720 \mathrm{~cm}^{-1}$, respectively.

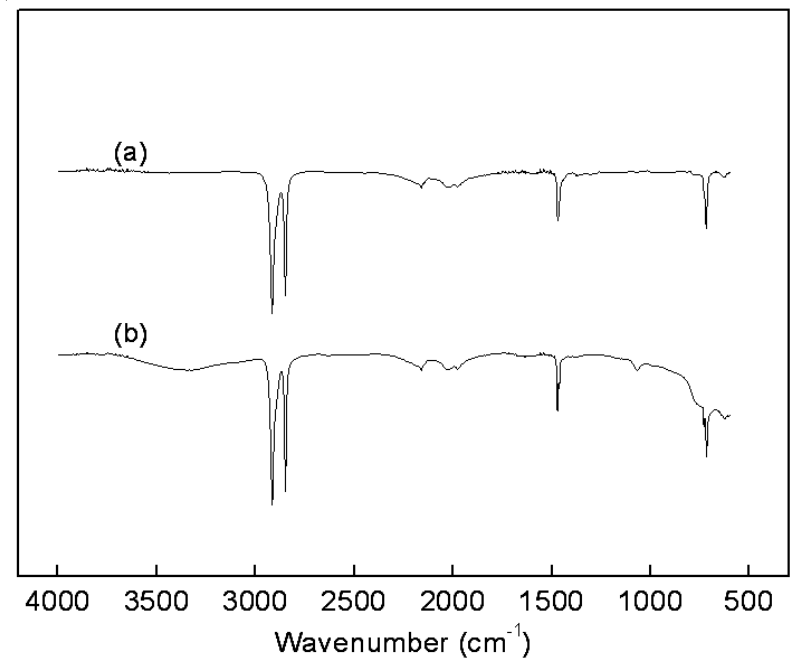

Fig. 1. FT-IR spectra of (a) insoluble parts after soxhlet processing with hexane for poly(ethylene-ter-1-decene-ter- $p$-methylstyrene) by run 5 and (b) polyethylene by run 1

These results show that the soxhlet process separated the insoluble homo polyethylene (some types of byproducts) from the terpolymer, which was the soluble part.

Fig. 2 shows the ${ }^{13} \mathrm{C}$ NMR spectra of the poly(ethyleneter-1-decene-ter- $p$-methystyrene) by run 5. Ortho and meta carbon atoms were observed in the benzene ring. The carbon atom at the ortho position was ortho plus meta to the substituents and the carbon atom at the para position was meta plus para, being $123.2 \mathrm{ppm}$ and $124.1 \mathrm{ppm}$, respectively.

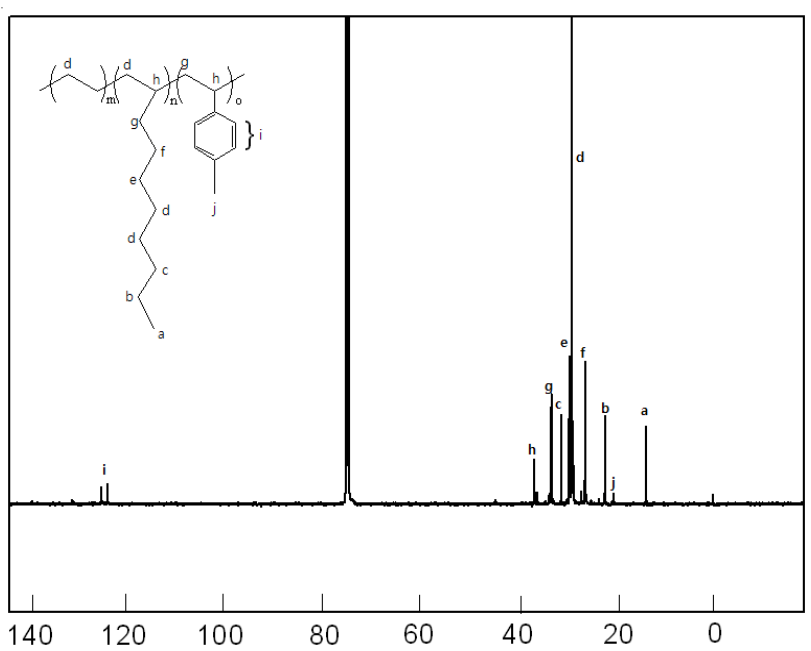

Fig. 2. ${ }^{13} \mathrm{C}$ NMR spectrum of poly(ethylene-ter-1-decene-ter- $p$ methylstyrene) by Run 5

The peak for the $\mathrm{CH}_{3}$ group of $p$-methyl styrene ( $p$-MS) was detected at $21 \mathrm{ppm}$. Methyl group substitution at the para- position was expected to have little effect on the chemical shifts of the methylene and methine carbons in the polymer backbone. In addition to the two chemical shifts (21.0 and 29.8 ppm), corresponding to the methyl carbon from $p$-methyl styrene and methylene carbons from ethylene, respectively, there was one peak (37.0) corresponding to methane carbons from the $p$-methyl styrene units, which were separated by multiple ethylene units along the polymer chain ${ }^{14}$.

Fig. 3 presents the ${ }^{1} \mathrm{H}$ NMR spectra of poly(ethylene-ter1-decene-ter- $p$-methy styrene) with different 1-decene feed molar concentrations. The signatures near $7.0 \mathrm{ppm}$ corresponded to the aromatic peaks of $p$-MS. The peaks for $\mathrm{CH}$, $\mathrm{CH}_{2}$ and $\mathrm{CH}_{3}$ groups of ethylene or 1-decene appeared in the range 0-3 ppm. The peaks for the $\mathrm{CH}_{3}$ group of 1-decene and $p$-MS were observed at 0.9 and at $2.3 \mathrm{ppm}$, respectively. The peak for the $\mathrm{CH}$ of 1-decene was noted at $1.5 \mathrm{ppm}$. Compared to the peaks for the $\mathrm{CH}_{3}$ group of $p$-MS, the $\mathrm{CH}_{3}$ group of 1-decene or ethylene occupied a relatively broad area.

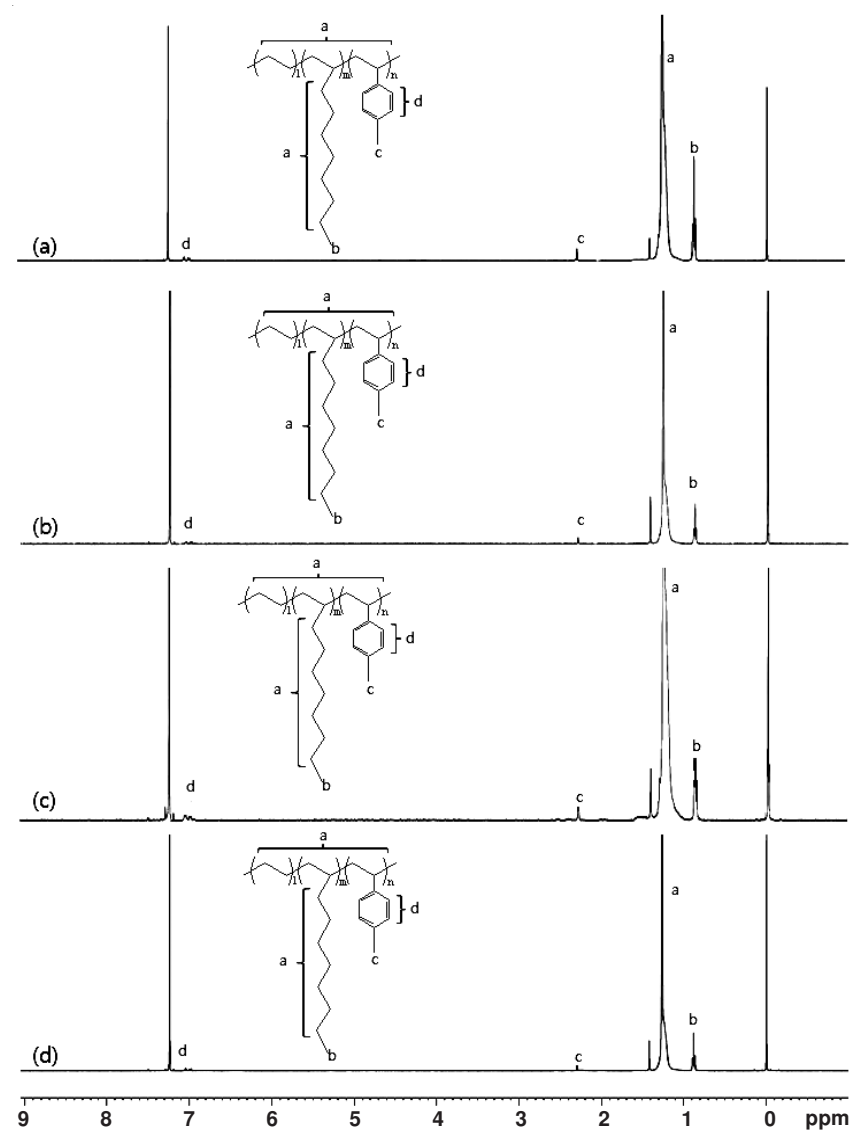

Fig. 3. $\quad{ }^{1} \mathrm{H}$ NMR spectra of poly(ethylene-ter-1-decene-ter- $p$-methylstyrene) by run 7 , (b) run 5 , (c) run 8 and (d) run 9

Fig. 4 shows the wide-angle X-ray scattering (WAXS) data for polyethylene by run 1 and the terpolymers with different 1-decene feed molar concentrations. Three peaks were observed in the wide-angle X-ray scattering data for all the terpolymers, whereas there were two peaks in the wide-angle $\mathrm{X}$-ray scattering data for polyethylene, which only presented a crystalline phase.

The broad amorphous peaks in the wide-angle X-ray scattering data of the terpolymers near $19.5-20^{\circ} 2 \theta$ were assigned to 1 -decene and $p$-methyl styrene. The broad 
amorphous peaks increased with increasing 1-decene content in the case of the terpolymers by runs 5,7 and 8 . Two other small peaks in the terpolymers were also present at $21.8^{\circ}$ and $24.3^{\circ} 2 \theta$ indicating the crystalline phase of the terpolymers. This suggests that the terpolymers were partially crystalline, even though the crystallinity was decreased substantially by the insertion of comonomers or termonomers.

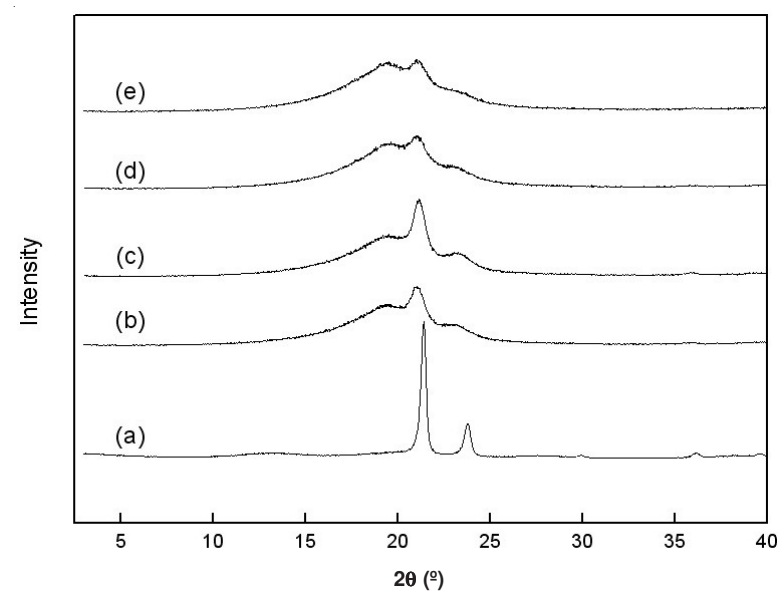

Fig. 4. Wide-angle X-ray scattering data for the polymers by (a) run 1, (b) run 7, (c) run 5 , (d) run 8 and (e) run 9

Fig. 5 shows the DSC thermograms for the terpolymers as a function of the 1-decene/p-methyl styrene feed molar ratio. The upper and lower areas show the variation in the second cooing and third heating curves of the polymers, respectively.

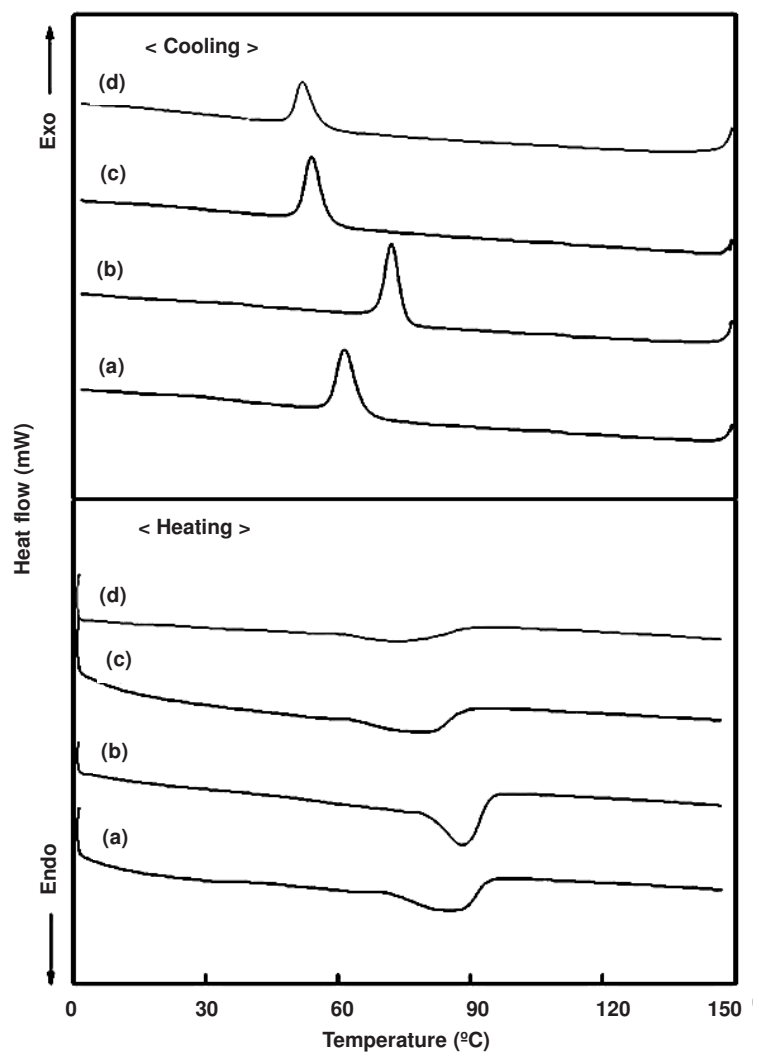

Fig. 5. DSC cooling and heating thermograms for the terpolymers with a different 1-decene/p-MS feed molar ratio: (a) 0.5, (b) 1, (c) 1.5 and (d) 2
The crystallization temperatures $\left(\mathrm{T}_{\mathrm{m}}\right)$ and melting temperatures $\left(\mathrm{T}_{\mathrm{c}}\right)$ of the terpolymers were examined. Table- 2 summarizes the $\mathrm{T}_{\mathrm{c}}, \mathrm{T}_{\mathrm{m}}, \Delta \mathrm{H}_{\mathrm{m}}$ and crystallinity of the terpolymers measured by DSC and wide-angle X-ray scattering as a function of the 1-decene feed molar concentration.

\begin{tabular}{ccccccccc}
\hline \multicolumn{8}{c}{ TABLE-2 } \\
\multicolumn{8}{c}{$\mathrm{T}_{\mathrm{c}}, \mathrm{T}_{\mathrm{m}}, \Delta \mathrm{H}_{\mathrm{m}}$ AND CRYSTALLINITY OF THE TERPOLYMER } \\
AS FUNCTION OF THE 1-DECENE FEED \\
MOLAR CONCENTRATION
\end{tabular}

The $\mathrm{T}_{\mathrm{m}}$ and $\mathrm{T}_{\mathrm{c}}$ of the terpolymers decreased with increasing 1-decene/ $p$-methyl styrene feed molar ratio from 1 to 2 . As shown in Table-1, the compositions of 1-decene in the terpolymers increased with increasing 1-decene feed molar concentration. An increase in the 1-decene content in the terpolymers resulted in a decrease in the crystallinity of the terpolymers. This can explain why $\mathrm{T}_{\mathrm{m}}$ and $\mathrm{T}_{\mathrm{c}}$ decreased with increasing 1-decene/pmethyl styrene feed molar ratio from 1 to 2 .

Fig. 6 shows the change in the loss tangent $(\tan \delta)$, dynamic storage modulus and loss modulus of the terpolymers prepared using different 1-decene feed molar concentrations. Table-3 lists the DMA data for the terpolymerization according to the 1-decene feed molar concentration. $\mathrm{T}_{\mathrm{g}}$ is the dominant transition in amorphous polymers or semicrystalline polymers with an amorphous region. All the terpolymers had a $\mathrm{T}_{\mathrm{g}}$ of approximately $-30{ }^{\circ} \mathrm{C}$, which suggests that the terpolymers in this system are quite flexible at room temperature.

TABLE-3

DMA DATA FOR THE TERPOLYMERIZATION ACCORDING TO THE CHANGES IN THE 1-DECENE FEED MOLAR CONCENTRATION

\begin{tabular}{|c|c|c|c|c|c|c|c|}
\hline \multirow{2}{*}{$\begin{array}{l}\text { Run } \\
\text { no. }\end{array}$} & \multicolumn{3}{|c|}{ Monomers (mol/L) } & \multirow{2}{*}{$\begin{array}{c}\text { Storage } \\
\text { modulus } \\
(\mathrm{MPa})\end{array}$} & \multirow{2}{*}{$\begin{array}{c}\text { Loss } \\
\text { modulus } \\
(\mathrm{MPa})\end{array}$} & \multirow{2}{*}{$\begin{array}{c}\text { Tan } \\
\delta\end{array}$} & \multirow{2}{*}{$\begin{array}{c}\mathrm{Tg} \\
\left({ }^{\circ} \mathrm{C}\right)\end{array}$} \\
\hline & $\mathrm{E}^{\mathrm{b}}$ & $\mathrm{D}^{\mathrm{c}}$ & $\mathbf{M}^{\mathrm{d}}$ & & & & \\
\hline 7 & 0.4 & 0.2 & 0.4 & 650 & 98 & 0.08 & -31.0 \\
\hline 5 & 0.4 & 0.4 & 0.4 & 640 & 89 & 0.09 & -25.8 \\
\hline 8 & 0.4 & 0.6 & 0.4 & 160 & 27 & 0.11 & -30.7 \\
\hline 9 & 0.4 & 0.8 & 0.4 & 328 & 64 & 0.14 & -34.8 \\
\hline
\end{tabular}

${ }^{a}$ Polymerization conditions: $\mathrm{rac}$-Et(Ind) $\mathrm{ZrCl}_{2}, \mathrm{MAO}$, catalyst $=2.5$ $\mu \mathrm{mol}$, cocatalyst $=\mathrm{MAO},[\mathrm{Al}] /[\mathrm{Zr}]=3000,50^{\circ} \mathrm{C}, 30 \mathrm{~min} ;{ }^{\mathrm{b}}$ Ethylene; ${ }^{\mathrm{c}} 1$-decene; ${ }^{\mathrm{d}} p$-methylstyrene

Fig. 7 shows the changes in the $\mathrm{T}_{\mathrm{g}}$ and $\mathrm{T}_{\mathrm{m}}$ of the terpolymer as a function of the 1-decene content in the feed. As the 1-decene feed molar concentration increased from 0.2 to 0.8 $\mathrm{mol} / \mathrm{L}$, the $\mathrm{T}_{\mathrm{g}}$ of the terpolymer showed a maximum value at $-25.8^{\circ} \mathrm{C}$, which then decreased to $-34.8^{\circ} \mathrm{C}$.

The decrease in $\mathrm{T}_{\mathrm{g}}$ with increasing 1-decene concentration in the feed from 0.4 to $0.8 \mathrm{~mol} / \mathrm{L}$ was attributed to the decrease in free volume or increase in rigid $p$-methyl styrene 
in the terpolymers. Compared to the terpolymer by run 5 , the terpolymer by run 8 had a low $p$-MS composition, which resulted in a decrease in chain stiffness and free volume of the terpolymer by run 8 . On the other hand, the $\mathrm{T}_{\mathrm{g}}$ of the terpolymer by run 9 was lower than that by run 8 . This was explained by increasing free volume caused by the higher 1-decene contents in the terpolymer by run 9 than that by run 8 , even though the rigid $p$-MS contents of the terpolymer by run 9 was slightly higher than those of the terpolymer by run 8 .

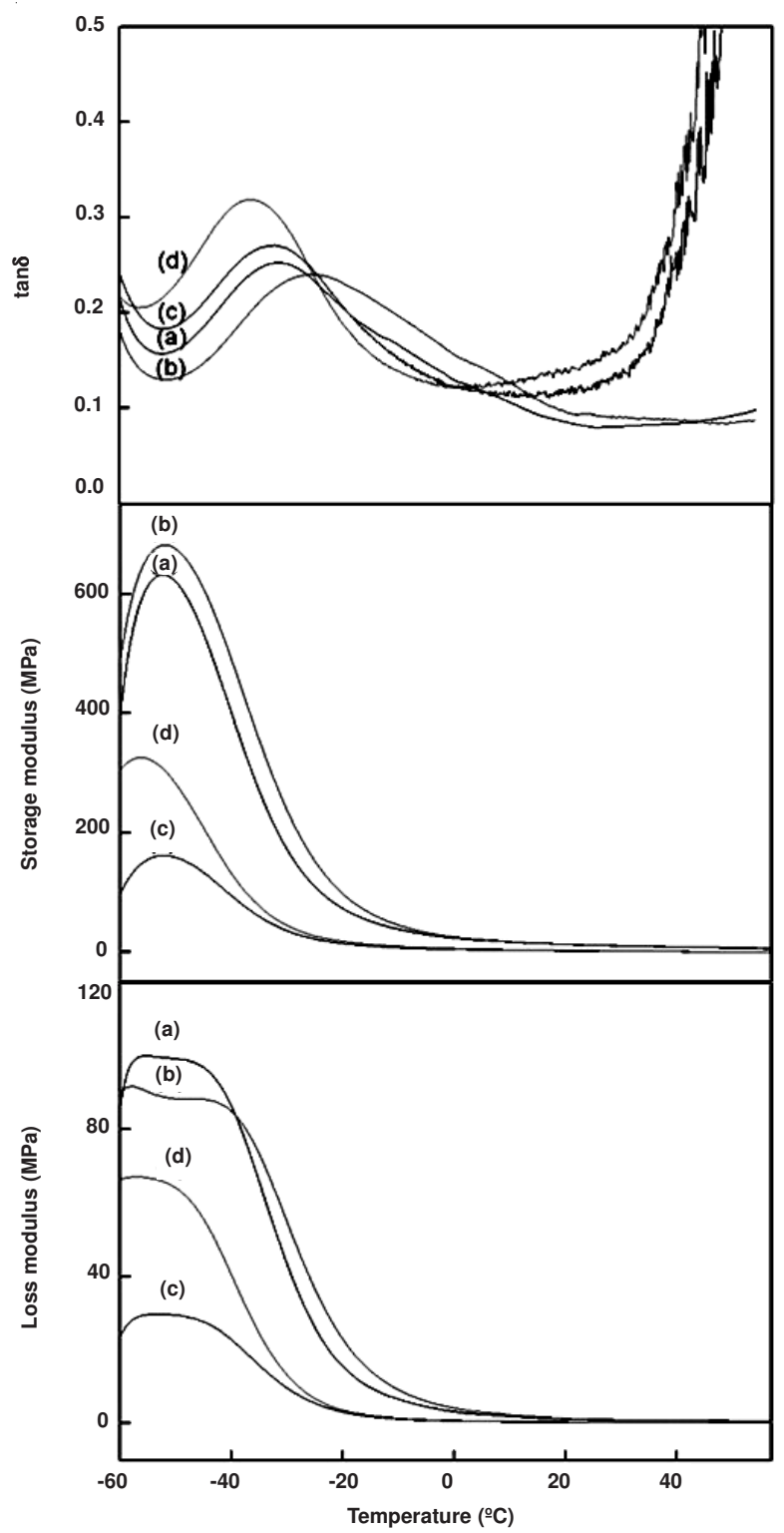

Fig. 6. Changes in $\tan \delta$, storage and loss modulus of the terpolymers by (a) run 7, (b) run 5, (c) run 8 and (d) run 9

\section{Conclusion}

Various homopolymers, copolymers and terpolymers comprized of ethylene, 1-decene and $p$-methylstyrene were synthesized using a rac-Et(Ind) ${ }_{2} \mathrm{ZrCl}_{2}$ catalyst and methylaluminoxane cocatalyst system. The structures and compositions of the polymers were characterized by ${ }^{13} \mathrm{C}$ and ${ }^{1} \mathrm{H}$ NMR spectroscopy and the catalytic activity, weight-averaged molecular weight, number-averaged molecular weight and molecular weight distribution of the polymers were also compared.

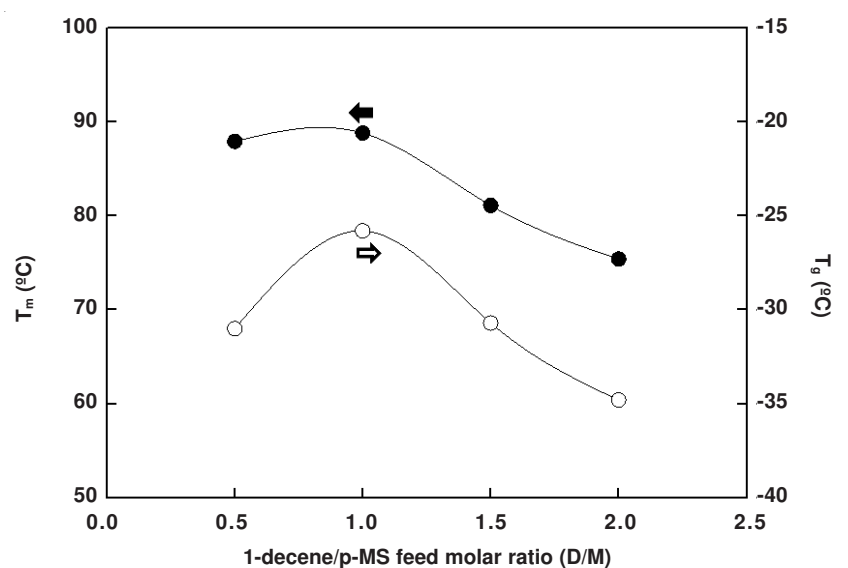

Fig. 7. Changes in $\mathrm{T}_{\mathrm{g}}$ and $\mathrm{T}_{\mathrm{m}}$ as a function of the 1-decene/ $p$-methyl styrene feed molar ratio

The catalytic activity, weight-average molecular weight and molecular weight distribution increased with increasing ethylene pressure from 0.1 to $0.4 \mathrm{~mol} / \mathrm{L}$. As the 1 -decene molar concentration in the feed was increased from 0.2 to $0.8 \mathrm{~mol} /$ $\mathrm{L}$, the catalytic activity increased sharply, due to the positive comonomer effect.

Wide-angle X-ray scattering showed that the terpolymers were partially crystalline but the crystallinity of the terpolymers decreased significantly with the insertion of comonomers and termonomers. The $\mathrm{T}_{\mathrm{m}}$ and $\mathrm{T}_{\mathrm{c}}$ of the terpolymers decreased with increasing 1-decene/ $p$-MS feed molar ratio from 1 to 2 due to a decrease in crystallinity. In contrast, the $\mathrm{T}_{\mathrm{g}}$ of the terpolymer had a maximum value at $-25.8^{\circ} \mathrm{C}$, which then decreased to $-34.8^{\circ} \mathrm{C}$.

\section{ACKNOWLEDGEMENTS}

This study was supported by the Fundamental R\&D Program for Core Technology of Materials funded by the Ministry of Knowledge Economy, Republic of Korea.

\section{REFERENCES}

1. W. Kaminsky, Metalorganic Catalysts of Synthesis and Polymerization: Recent Results by Ziegler-Natta and Metallocene investigations, Springer-Verlag:Berlin (1999).

2. R. Marconi, L. Boggioni, A. Ravasio, F.D. Colo, I. Tritto and U.M. Stehling, Macromolecules, 44, 795 (2011).

3. P. Shinjoon, W. Wen-Jun and Z. Shiping, Macromol. Chem. Phys., 201, 2203 (2000).

4. W. Wen-jun, K. Edward Z. Shiping, E. Archie and H.L. Lee, J. Polym. Sci., Part A, 37, 2949 (1999).

5. N. Naofumi and I.A. Yukio, Macromol. Chem. Phys., 203, 2155 (2002).

6. I. Kim, React. Funct. Polym., 49, 197 (2001).

7. F. Forlini, E. Pinci, I. Tritto, M. Sacchi and F. Piemontesi, Macromol. Chem. Phys., 203, 645 (2002).

8. S. Graef, U.M. Wahner, R. Van and A.J. Sanderson, J. Polym. Sci. Part A: Polym. Chem., 40, 128 (2002).

9. W. Kaminsky and H. Drogemuller, Makromol. Chem. Rapid Commun., 11, 89 (1990)

10. W. Mingkwan, P. Piyasan and J. Bunjerd, Molecules, 16, 373 (2011).

11. K. Nomura, H. Fukuda, S. Katao, M. Fujiki, H.J. Kim, D.H. Kim and I. Saeed, Macromolecules, 44, 1986 (2011).

12. K. Nomura, H. Fukuda, S. Katao, M. Fujiki, H.J. Kim, D.H. Kim and S. Zhang, J. Chem. Soc., Dalton Trans., 40, 7842 (2011).

13. P.J. Flory and A.J. Vrij, J. Am. Chem. Soc., 85, 3548 (1963).

14. T.C. Chung and H.L. Lu, J. Polym. Sci. Part A: Polym. Chem., 35, 575 (1997). 